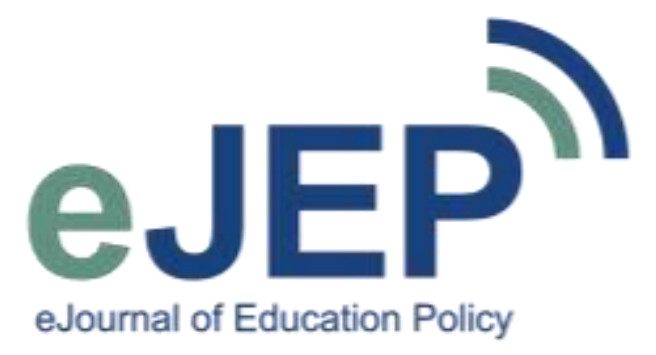

\title{
Could Proactive Local Policy Improve Principals' Building-Level Leadership of Special Education Services?
}

To cite this article: Hughes, T., Bechtler, M., Cruz-Szabo, G., Hafner, L., Ortiz, L., Piel, K., Quiroz, S., \& Robbins, T. (2020). Could Proactive Local Policy Improve Principals' BuildingLevel Leadership of Special Education Services? eJournal of Education Policy, 21(2). https://doi.org/10.37803/ejepF2002

Thomas Hughes, Ph.D.

Melissa Bechtler, M.Ed.

Gina Cruz-Szabo, M.Ed.

Liesl Hafner, M.Ed.

Laci Ortiz, M.Ed.

Kayla Piel, M.Ed.

Stephanie Quiroz, M.Ed.

Teresa Robbins, M.Ed.

Northern Arizona University

\begin{abstract}
Special education is a vital and challenging area of service within American education. The services it provides and the processes which are employed are highly articulated and regulated by an extensive network of federal and state laws. Policy tends to drive decision making processes and accountability more than it guides instruction, decisions about leadership or efforts to promote unity among stakeholders in the schools. Those remaining responsibilities rest with onsite administrators who may not always have an abundance of training or experience in the area of special education. This article focuses on practical issues, enhancements, and voluntary policy considerations that could help promote greater harmony and therein contribute to greater special education success. Starting with findings from an Arizona study that confirmed training oversights, the article illuminates the types of situations that can slow progress and even overwhelm untrained leaders. The article concludes by suggesting changes in the way administrators approach special education coupled with proactive policy recommendations intended to nurture a greater sense of collaboration throughout American schools.
\end{abstract}

Keywords: Special education, policy, special education law, effective leadership, administrator training, teacher retention, conflict 


\section{Introduction}

Special education services have been mandated in the United States since 1975 when the Education for All Handicapped Children Act was authorized by Congress and signed into law by President Ford (Bjorn, Aro, Koponen, Fuchs \& Fuchs, 2015, Hickman, 2017). Since that time, the landmark legislation has received ongoing updates with revisions occurring as often as once or even twice a decade (Hickman, 2017). Though the motivation prompting these regular updates should generally be assumed to be well-intended, the resulting changes delivered to schools have often been complicated and challenging. Of late, the shift in focus to a ResponseTo-Intervention (RTI) approach combined with the advent of Results-Driven Accountability (RDA), has yielded a marked change in emphasis. This shift has affected decision-making, prioritizing individual student needs, as well as evaluation of overall services being provided (Bjorn et al., 2015; Hickman, 2017).

The updated results-driven approach just referenced has been years in the making. In fact, implementation of RTI has been underway for more than a decade. However, there remains an ongoing tension between the parties (regular and special education, as well as parents) responsible for and invested in the well-being of special needs students (Cochran-Smith \& Dudley-Marling, 2012). As the Education for All Handicapped Children Act has undergone updating, including being renamed the Individuals with Disabilities Education Act (IDEA) in 1990, numerous studies have been carried out to gauge its effectiveness and critique the underlying approaches being implemented. Some of the emphasis has targeted governmental agency responsibilities (Hickman, 2017), and other efforts have taken on a more systemic perspective (Fuchs, Fuchs \& Compton, 2012). Additional examination of teacher perceptions and challenges have also been pursued (Werts \& Carpenter, 2013).

The underlying emphasis guiding this article addresses the building-level leadership implications associated with narrowing the divide between regular and special education (Bjorn et al., 2015). Further, this project addresses the gaps between skills principals need to be capable leaders and active contributors even in the area of special education, and the lack of training they receive in support of developing said abilities. Graduate students completing their administrative training know full well that their learning is not complete when they accept their diploma. As is advanced through this article, however, many also realize that the lack of training they receive concerning special education is especially troubling. Practitioners in the field have confirmed these concerns through their participation in recently completed research. Further, a group of student scholars committed to increasing their awareness of this topic opted to address this issue through the applied research disseminated here.

\section{Statement of the Problem}

Building-level educational leaders continue to face increasingly complex challenges that often outstrip their formal training (Hughes, 2014; Hughes, 2019; Miller, 2018; Fullan \& Kirtman, 2019). Though school systems often have access to specialized leadership to oversee special education processes, the delivery of instruction, as well as daily dealings with students, parents, and staff, takes place within the purview of building-level leadership. As new data confirms, the responsibility to quickly, efficiently, and physically oversee potentially explosive situations that represent the top source of litigation in education rests with well-intended building leaders. 
These are the same administrators, however, who reported they rarely receive adequate preparatory training to carry out this mission as it relates to special education.

Building on confirmed training deficits, this project set out to identify the types of special education-oriented issues that regularly challenge the training and experience of school administrators and therein limit the likelihood of successful leadership. The narrative presented here sets out to illuminate these situations and subsequently offer insights concerning possible positive action steps. The article also advocates for policy development that is more proactive towards inspiring effective leadership to effectively and sustainably satisfy restrictive and compliance-centered federal and state laws and local policies.

\section{Discussion of the Literature}

Though relatively short-lived, the history of implementation for special education presents a pattern where the role of the building-level administrator has come full circle from high levels of involvement - to becoming increasingly removed - and back to needing to be directly involved. Special education services originally emerged at the state level and became a national initiative after the passage of landmark legislation in 1975 (Hickman, 2017). Without the benefit of established teacher training programs to rely upon for securing special educators (Esteves \& Rao, 2008), many schools initially employed substitute teachers and other willing parties to provide early services. As structure and increased expectations quickly developed, the effort to define appropriate education took precedence (Esteves \& Rao, 2008), and roles became increasingly specialized, with monitoring and compliance becoming more prominent considerations as well. Leadership, which was initially generalized, became more specialized, as school psychologists and special services directors emerged to become the off-site managers of the expanding range of services and processes.

With schools facing increased accountability, pressures in academic, financial, and personnel areas, administrative roles continued to evolve in a more specialized fashion. Ultimately principals assumed the role of "instructional leader," which effectively aligned them with traditional regular education responsibilities. Special education, operating in schools under separate management and expanding requirements, increasingly found itself looking across a divide described by Bjorn et al., (2015). Following these developments, the regulatory aspects of special education have only continued to strengthen. Policy is far less likely to be locally written and is increasingly driven by factors other than instructional pedagogy. Coinciding with the expanding "compliance mentality" that schools and their leaders face (Hughes et al., 2019), building-level leaders are often left to cope the best they can with daily demands which often find the rights of the special needs students at odds with the rights of other students and staff members.

While the procedural considerations schools face usually receive oversight through centralized student services structures, the daily decisions, interventions, and remedies that occur instantaneously at the classroom and building levels are typically displaced from centralized monitoring. Some would suggest that the prevailing situation leaves special educators in a literal no-mans-land, there they often have to fend for themselves - and may even need to tell building leaders what needs to be decided when situations call for administrative intervention. Thirty years ago, building leaders were the masters of their domain (Hughes and Davidson, 2020). In 
2020, specialization and the increased complexity of issues, in general (Hughes, 2014; Hughes 2019; Miller, 2018; Fullan \& Kirtman, 2019), has left many building-level administrators as a stranger in their school when they frequently depend on others to contend with challenging special education issues.

\section{Legal Considerations}

Decker and Brady (2016) have cited the increasing prevalence of lawsuits associated with special education services as an ongoing challenge that necessitates improvements in the building-level responses to increasingly complex situations and overall staff preparation. Decker (2014), has also cited the general need to better equip all staff at all levels with an improved understanding of legal issues and their ramifications. The escalation in tensions surrounding students with disabilities has placed an additional onus on school-level employees (Decker \& Brady, 2016) to evaluate and effectively respond to numerous demands.

Expecting after-the-fact resolution to be delivered by the involvement of the off-site student services director, often proves to be too late in the cycle of events to remain a viable approach for overseeing special needs services. Ultimately, in calling for higher capacity to respond to challenging situations at the building level, Decker (2016) reinforced the argument that the principal and the administrative team at the building level play a crucial role. They need to step up and play a more substantial part in leading in the area of special education - and therein hopefully also contribute to narrowing the divide referenced by Bjorn et al., (2015) as a result.

\section{Training Deficits}

The need to better address the delivery of services for special needs students at the building level (Decker \& Brady, 2016) is both a reasonable objective and perhaps even an urgent one. An indirect case in support of this position comes through national training standards for school administrators (National Policy Board for Educational Administration, 2015). However, overreliance on standards has been criticized by some (English \& Ehrich, 2016). Further, even with a history of standards being established and supported, continued specialization within school administration has resulted in multiple areas where newly trained administrators often feel ill-equipped to carry out the duties that are assigned to them.

Drawing from survey data collected with the assistance of the Arizona School Administrators Association (AZSA.org) to better document these perceptions, recent literature has shown that training is perceived by administrators to be lacking in multiple areas. Among the most important are critical thinking (Hughes, 2019; Hughes et al., 2019), conflict resolution (Hughes, Hughes, 2019; Hughes \& Davidson, 2020) as well as hiring practices (Hughes, 2019; Hughes \& Davidson, 2020).

Collaboration with AZSA has also yielded similar information about preparedness relative to special education, which will be addressed later within this article. Examined collectively, the message that can be taken from this body of work is that it would appear building-level leaders hold the right position to impact improvement, but often lack the necessary preparation to make an effective contribution to the development, delivery, and defense of special education services when called upon to do so. 


\section{Unique Perspectives}

The data and the literature just cited likely provide sufficient reason to question the special education preparedness of building leaders. However, there is additional insight worth considering. Research has increasingly drawn from professionals responding while embedded within their work settings. Such a phenomenological approach allows for the exploration and communication of shared experiences and collective meaning (Creswell \& Poth, 2018). It has proven to be a productive contributor to scholarship targeting our understanding of leadership development in general (Jenkins, 2019). The approach has also benefited efforts to examine matters such as legal literacy more specifically (Schneider, 2020).

When examining the need to increase attention to problem-solving abilities during principal training, Hughes, Caslin, Foss, Larsen, Loffer, and Sacco (2019), drew from the embedded vantage point of graduate students preparing to become school administrators. Their unique views were particularly insightful because they were still highly engaged in the classroom and leadership roles while completing graduate training and internships at the same time. It is not unusual for these fledgling administrators to contemplate how they will address inevitable challenges (Hughes \& Mouw, 2017), that are only increasing in intensity and complexity (Hughes, 2014; Hughes, 2019; Miller, 2018; Fullan \& Kirtman, 2019).

\section{Methodology}

As was undertaken with an examination of training deficits having to do with problem-solving skills (Hughes et al., 2019), this article drew extensively from the unique positioning and heightened perspectives of educators training to become school administrators. When questioned about areas where they needed to know more following completion of their master's program, the group quickly identified special education as a primary area of concern. Their insights about their continued needs were confirmed by original special education survey information recently collected from Arizona school administrators.

Proceeding from a grounded reflective approach that examined the intersection of legal mandates with daily practice, the student-researchers collaboratively identified the most pressing and most overlooked issues that they came across in practice. These pressing issues were identified, defined, and examined in terms of possible daily practice, training, and policy solutions. This activity was carried out throughout a 5-month time-frame and relied on multiple reflective analytic and reflexive practices. These efforts included reviewing the literature, documenting interactions in the work setting, and journaling. In addition, they participated in organized discussion boards, combined written response with reflection, and undertook group discussion, prompted reflection, group writing, and finally, active critique and refinement of the article itself.

\section{Participants}

Seven female graduate students completing their school administrator training joined in an investigative effort to enhance their leadership abilities as it related to the delivery of special education services at the building level. Of the seven students, five were currently in the classroom setting, with two having assistant-level administrative responsibilities. Two indicated past or continued experience with special education. Total educational experience ranged from seven years to eighteen years in education, with work settings distributed across six states. The majority of members possessed elementary experience, though some also had middle-level and 
secondary expertise. A final detail sheds important light on the vantage point of this investigative group. When asked how many different lead principals they worked under during their careers, the combined response indicated tremendous turnover with a change in leadership occurring every 1.7 years. Discussion later in this article will touch on the implications of that turnover rate.

\section{Limitations}

Limitations exist with all research and scholarship. This article draws from a variety of sources, including recent literature, original state-wide survey data, and the combined perspectives of uniquely positioned student-researchers with professional experience in multiple states across America. The observations, recommendations, and general remedies outlined in this article may not be completely applicable in all locations or situations. Still, there is an abundance of useful information and thought-provoking perspective, that can benefit interested school leaders and policy makers across the United States.

\section{Survey Results}

Despite the longstanding influence of national training standards, research has revealed multiple important skill areas where school administrators self-reported a lack of sufficient preparatory training. Conflict resolution skills (Hughes, 2019) and critical thinking skills (Hughes, 2019; Hughes et al., 2019) have already been documented as important but overlooked areas of focus during training for building-level leaders. Survey data collected from Arizona school administrators drew from all leadership levels and also included an examination of perceptions toward working knowledge of special education.

Results represented in Table 1.0 are revealing. Taken on a whole, knowledge of special education received a similar response to perceptions concerning conflict resolution and critical thinking in that there was little if any "middle of the road" result such as neither agree/disagree. Similarly, roughly $10 \%$ of the administrators who responded replied "disagree" or "very strongly disagree" to the representation that any of the three were important. Finally, of the three skill areas, knowledge of special education received the most substantial ranking of "very strongly agree" of any of the three skill areas, with 55\% of participants making that distinction, compared to $48 \%$ for conflict resolution and only $38 \%$ for critical thinking. 
Table 1

Importance of Working Knowledge

\begin{tabular}{|c|c|c|c|c|c|c|}
\hline \multirow[b]{2}{*}{ Variable } & \multicolumn{2}{|c|}{$\begin{array}{l}\text { Conflict } \\
\text { Resolution } \\
(\mathrm{N}=126)\end{array}$} & \multicolumn{2}{|c|}{$\begin{array}{l}\text { Critical } \\
\text { Thinking } \\
(\mathrm{N}=125)\end{array}$} & \multicolumn{2}{|c|}{$\begin{array}{l}\text { Special } \\
\text { Education } \\
(\mathrm{N}=127)\end{array}$} \\
\hline & $\mathrm{N}$ & $\%$ & $\mathrm{~N}$ & $\%$ & $\mathrm{~N}$ & $\%$ \\
\hline Very Strongly Agree & 60 & 47.6 & 47 & 37.6 & 70 & 55.1 \\
\hline Strongly Agree & 49 & 38.9 & 49 & 39.2 & 38 & 29.9 \\
\hline Somewhat Agree & 4 & 3.2 & 15 & 12.0 & 6 & 4.7 \\
\hline Neither Agree/Disagree & - & - & 2 & 1.6 & - & - \\
\hline Somewhat Disagree & - & - & - & - & - & - \\
\hline Strongly Disagree & 4 & 3.2 & 4 & 3.2 & 4 & 3.1 \\
\hline Very Strongly Disagree & 9 & 7.1 & 8 & 6.4 & 9 & 7.1 \\
\hline
\end{tabular}

All three skill areas, conflict resolution, critical thinking, and knowledge of special education, were considered to be valuable by responding administrators. Special education and conflict resolution both received a response of roughly $85 \%$ indicating strong agreement or very strong agreement to the idea that the abilities were essential. Critical thinking, though also necessary, received approximately a $77 \%$ response to the same proposition. Each of the three skill areas was also addressed with respect to the type of training administrators received for the ability area. Results, shown in Table 2, present positive information in as much as $10 \%$ of administrators reported receiving detailed training in special education, whereas only $2.4 \%$ responded similarly for conflict resolution, and only a single respondent $(0.8 \%)$ reported receiving devoted coursework for critical thinking.

The survey utilized for collecting this data did not probe into what the training entailed. Further, it is possible that the training reported for special education could have resulted from a dual major in regular and special education. While positive in comparison to the shortage of devoted coursework made available for conflict resolution and critical thinking, the overall training trends realized for special education are not positive, as $80 \%$ of respondents reported receiving no direct preparation or occasional mention of the topic at best. This deficit projects the potential for struggle when building leaders asked to provide leadership during challenging special education situations. 
Table 2

Extent of Graduate Preparation

\begin{tabular}{|c|c|c|c|c|c|c|}
\hline \multirow[b]{2}{*}{ Variable } & \multicolumn{2}{|c|}{$\begin{array}{l}\text { Conflict } \\
\text { Resolution } \\
(\mathrm{N}=127)\end{array}$} & \multicolumn{2}{|c|}{$\begin{array}{l}\text { Critical } \\
\text { Thinking } \\
(\mathrm{N}=127)\end{array}$} & \multicolumn{2}{|c|}{$\begin{array}{l}\text { Special } \\
\text { Education } \\
(\mathrm{N}=127)\end{array}$} \\
\hline & $\mathrm{N}$ & $\%$ & $\mathrm{~N}$ & $\%$ & $\mathrm{~N}$ & $\%$ \\
\hline Devoted Course & 3 & 2.4 & 1 & 0.8 & 13 & 10.2 \\
\hline Work Within Course/Program & 15 & 11.8 & 6 & 4.7 & 13 & 10.2 \\
\hline Occasional Work/Mention & 69 & 54.3 & 78 & 61.4 & 74 & 58.3 \\
\hline No Direct Preparation & 40 & 31.5 & 42 & 33.1 & 27 & 21.3 \\
\hline
\end{tabular}

As reported earlier, the researchers involved in this investigation were already of a mind that special education was an overlooked topic in their training. The confirmation they received by examining the information in Table 1 and Table 2 clearly reinforced their perceptions. Further, it fueled their interest in documenting some of the ramifications of said training deficits, so that they could better advocate for improved training as well as the development of supportive policies at the public-school level. Their insights concerning shortcomings, solutions, and possible policy supports follow.

\section{Participant Insights}

As described earlier, Schneider (2020) drew insights from 10 graduate students. Hughes et al., (2019) drew from five graduate students when addressing critical thinking skills. A total of seven graduate students participated in the process described in this article. Ahead of detailing the insights, perceived shortcomings, and conclusions drawn by the group, two caveats deserve mention. First, the reflective ideas being shared will be concerned with how the group perceived things to be - now. The extension of these thoughts and considerations resulted in reflexive insights, which more closely represent how the group has reconsidered and even reframed situations, needs, and challenges. These thoughts will be shared separately in the form of recommendations for policy development. Also, second to this, the group delved into the matter of the "divide" described by Bjorn et al., (2015). In the eyes of the researchers, the divide between regular education and special education staff and services is widely evident. It is also indicative of a macro-level over-arching compliance mindset, as well as a series of recurring situations that could be viewed as being more micro-level.

The group identified four vital issues in total. Each was applicable across multiple settings and proved to be the types of challenges where compliance interests were at least partly responsible for ensuing problems. The individual issues are detailed separately. They are represented in such a way as to include both explanation and personal insights associated with the situation. This includes where the circumstances appear to originate from, and the consequences of said developments. By all appearances, the issues also seem to be interrelated, and the overlap between them suggests that remedies to them could potentially be combined as well. The problems are addressed next. Possible solutions to these situations will be discussed afterward. 


\section{High Expectations}

If there is one ideal the literature and quality training programs both emphasize for future principals, it is that the establishment of high expectations for all students is a must. Principals that supervised this study group regularly started their year with opening statements concerning these high expectations. While special education was not excluded outright from these stated expectations, it was seldom emphasized according to shared experiences. As a result, years of daily interactions and observation concerning special education's standing - shared within the research group -established a pattern of growing complacency rather than one of excellence.

Mader (2017) described how this "delayed by default" mentality trapped students' instruction at tested deficit levels rather than pushing for grade-level targets and instruction that could provide them with a chance at real growth and success. Principals who stood apart and chose to create high expectations for special needs students would be the credible advocates so badly needed by the learners and their instructors. Instead, this team more typically experienced well-intended cheerleaders who made expected complimentary statements concerning special education staff often while mostly lacking any genuine or personal insight into the unique challenges present in the field of exceptional needs.

\section{Barriers to Progress}

The lack of insight and understanding just mentioned extends well beyond administration and includes a significant portion of the remaining staff. Though this limited vision is directly linked to the matter of high expectations, it was seen as being so prevalent that it also stands alone. In the eyes of the researchers, this challenge indeed underscores the reality of the divide and stands out as an area where proactive policy could perhaps make its most significant impact. One of the most glaring symbols of perpetuated bias and misunderstanding uncovered through this project was the prevailing mindset that there are "your kids," and there are "my kids" within our schools. That break-in ownership not only sets the stage for the divide but also continuously reinforces it according to the shared experiences and insights derived from the positioned researchers responsible for this project. It is also but one example of the struggle that results from a lack of understanding that is, at the very least tolerated from the top.

A second contributing issue identified as a barrier to progress was the reality that special education keeps evolving, and there is so much to know. According to the group, regular education professionals frequently complain about excessive paperwork tied to special needs students in their classrooms. Beyond the paperwork, classroom teachers also need to keep up with recognizing and addressing unique learning needs, modified assignments and behavioral interruptions to classroom operations. Shared ownership and increased understanding are challenging to establish when teachers are regularly overwhelmed. It is even more of a struggle when there are no natural opportunities for bogged down exceptional need specialists to share insights with their classroom colleagues. The existing policy that drives identification timelines does not resolve this issue. A proactive policy that addresses improved approaches to collaborating in providing services could address this - if approved and implemented.

The third identified barrier was the visible lack of high expectations for the overall relationship between regular and special education that has been called "the divide" by Bjorn et al., (2015). 
Each member of the research group reflected on and responded to a series of questions as part of the development and refinement process for this article. The consensus resulting from work with over 40 building-level leaders was that most principals are well aware of the divide. However, few understand the dynamics in play - and almost none were seen as making any real effort to resolve it. In one instance, highly invested special education staff attempted to initiate a professional learning community (PLC) to address unmet needs - but the administration did not support it.

It was agreed that demonstrating more credible behavior would make the most positive impact of any step an administrator could attempt. Some observed those efforts directly, though only on a limited scale. Principals were largely seen as taking special educators for granted instead. They would do better for students and building culture if they held all parties accountable to each other as a team. It was also strongly believed that improved credibility and mutual accountability would enhance teacher retention efforts as well.

\section{Retention of Teachers}

Teacher retention is increasingly recognized as a growing problem across the United States (Ramos \& Hughes, 2020). Challenges surrounding the recruitment, selection, and retention of special education teachers have long stood out in the daily practice and communications of this group. With 81 unfilled special education positions at the start of the year in 6 Maricopa County school districts, circumstances do not appear to be improving, especially in Arizona. The lack of high expectations and ways in which special education teachers are looked down upon combined in the study group's judgement to contribute to the already heightened turnover rate.

More specifically, it was commonly understood within this group that special education teachers are known to be seen as second-rate by their colleagues. Classroom teachers have frequently voiced their perception that their workload is much higher than a teacher working with "only a few kids in small groups." In stark contrast, they express that they are working with up to 30 kids, with lesson plans for five subjects - five days of the week - and must complete all the associated grading and paperwork. Administrators compound this problem when they are seen pulling special education teachers for emergency coverage around the campus, sending the message that their work is less important than the work of classroom teachers. This recognized expression of disrespect makes it easier to understand why a special education teacher would feel less than supported and potentially interested in seeking a more supportive work setting.

\section{It Is All About Respect}

Respect, which is the fourth concept, was viewed as tying the other three together. If addressed properly, it was also deemed capable of establishing a direction toward possible solutions. Working through this project, and reflecting on their own experiences and research, one of the critical lessons that emerged, as a result, was how building leaders need to lend credibility and mutual respect to the practice of balancing regular services and special needs services. Sometimes special needs educators struggle with responding to direction from lower-level administrators who are not perceived as having credible knowledge of their subject matter. These same educators were said to be "on an island" and in need of real understanding - and support when needed the most. Credibility is crucial, and according to Hughes and Davidson 
(2020) is something that is earned and nurtured - not a privilege that comes along with an official title.

Too often, the demands and expectations continue to build and never seem to relent for special educators. With the Covid-19 pandemic closing down schools, every member of a school staff faced stresses they could not have been prepared for. While uncertainty and less than optimal results were allowed for, special educators were forced to determine and document whether compensatory service time was necessary for each student with an Individualized Education Program (IEP). Most people would contend that this was a once in a century challenge - and be glad we got through it. Special educators, on the other hand, were required to remediate their adaptations like no others. The legalities that drive this need are not derived from disrespect. However, there rarely seems to be genuine respect for the added level of expectation that these educators have to rise to meet.

Years ago, one of the authors worked in a district where contract negotiations put special educators in a position of disrespect. The rules developed from the bargaining agreement said teachers could leave much earlier at the end of the day if their professional duties for that day were fulfilled. In and of itself, the idea was a popular one and well supported. Problems developed when, on occasion, teachers were assigned to after school IEP meetings. Though at that time and in that state, teachers effectively only needed to make an initial appearance, the regular education staff viewed this time as an unnecessary imposition and complained.

The language that freed the teachers was result of a documented surplus of hours that their bargaining group presented to the governing board. The irony in the criticism that ensued was that the overwhelming balance of surplus hours leading to the agreement and supporting its continuation resulted from overtime logged by special education employees. In the case referenced here, the underlying inequities were addressed. However, that was the result of leadership that dared to deviate from compliance to a mentality that favored continuance to the status quo. According to Hughes et al., (2019) all too often we fail to engage in a critical examination of needs and opt to embrace the existing conditions instead.

\section{Possible Solutions}

The need to establish and nurture respect across the divide - as just described - is a critical construct. Beyond that, the need to develop a sense of urgency and help instill a passion for making a real and lasting difference is central to the underlying motivation of this advocacy effort. In states like Arizona, where this article originated, many districts outside of the urban setting lack a director of special services. Further, there is no specified training or required licensure for anyone who holds a special education leadership position in the state of Arizona. When decision makers lack the training to become better versed in special education, it is all too understandable why the problems documented her persist.

The school administrator training model and prevailing district organizational models are flawed in their dependence on someone from outside of the building being responsible for ensuring special education programs and services operate effectively on site. It rarely works as well as we would like to think. Conditions only stand to improve if the building-level leader accepts responsibility for closing the divide. However, they need to be better equipped to understand the 
needs of diverse learners and those who support them, as opposed to thinking support mounts to expressing total faith in a staff that they rarely see, and likely do not understand. Administrators are not trained to meet these needs. As such, the experiences and observations shared within this article represent the continued potential for struggle and even legal challenge.

\section{Expecting Excellence}

Repairing the divide by expecting ownership and investment from building-level administrators does not appear to be a probable result of the status quo promoted by standards, mandates and rigid compliance-centered policy. It will likely not take place with anything less than the development of proactive policy that prioritizes a focus on effective instruction, and effective leadership dedicated to supporting special education as well as regular education teaching. Central to the policy is the need to expect and inspire excellence in on-site professional development and shared commitment to all students being recognized as capable, relevant, and deserving to be well served. The building administrator needs to be identified as the critical agent and active catalyst in bringing this culture into being - across all parts of their building.

\section{Specific Focuses}

First, there is a strong need for empowered, informed, and passionate building administrators to push for grade-level standards, even for students with IEPs. Research has shown as high as 85 percent of students with disabilities can master general-education content if they receive educational supports. Supports can include access to a special-education teacher, having test questions read aloud, or being allowed to sit in a specific part of the classroom (Mader, 2017). Due to such a strong history of adapting instruction to the level a student tests at, the push for grade-level standards being taught to special education students needs to come from administrators. Administrators need to see value in providing this instruction to their students to promote growth for their students. Though they may require added time for challenging tasks, special education students are highly capable and need to be shown just how much they can do. If administrators choose not to utilize this approach, they must be prepared to face the repercussions.

Second, school leaders need to develop a better understanding of the unique stresses a special education teacher experiences as well as craft a plan to provide training and support for this segment of their staff. A practice where an administrator shadows a veteran special education teacher (either on their campus or another one in the district) would be a practical and affordable way for them to become familiar with special education issues. This shadowing program would need to be done throughout the year, so principals develop a better understanding of student achievement challenges and the associated paperwork that goes along with the job. Developing a better understanding of the role of special education teachers would aid in creating a structured support system.

Third, beyond requiring added investment from building-level administration, district-level vision concerning educational policy needs to be enhanced as well. This concept was widely discussed during the principalship course, and also with those in the class who completed the prerequisite legal aspects course with the same instructor. District policy is increasingly crafted and supplied by external resources. These providers include state-level school board and professional associations, or else private legal resources that often cater to regional (multi-state) 
constituencies. Though it still possible to input on site, and final approval takes place locally, policy has increasingly been focused on compliance and avoiding litigation. This group believes said approach can potentially undercut a district's ability to effectively serve special needs students as advocated here by failing to recognize or address local realities in favor of a strong compliance focus (Hughes, 2019; Hughes et al., 2019; Hughes and Davidson, 2020).

\section{Proactive Policy}

Special education guidelines and policies lend themselves to defining processes and services directed toward students. They also include financial and staffing considerations. However, they do not address leadership practices, including the practical realities of potentially requiring specialized local training for administrators without a special education background. While zealous attention to policy can help ensure compliance with critically important processes, there is still a need to better attend to building-level considerations that can impact collaboration, motivation, and staff morale.

Returning to the reality that turnover in the classroom and at leadership levels neutralize gains that are made over time - there is only further need to proactively address change from a policy level. The positive message shared here is that policy can be enhanced. The following concepts are offered as specific elements that should be considered for inclusion into proactive policy that could address challenges identified in this article, and therein supplement and strengthen directives and practices that are already in place.

- Expand administrator capacity and investment by formally increasing evaluation expectations and establishing an annual training and performance goal tied directly to their growth and the success of the inclusive team-building efforts they have undertaken.

- Engage in local cross-training efforts (in house to the extent possible) where administration and non-special education staff gain practical, legal, and local insights into the lives, needs, and instructional approaches for all diverse learners within their buildings.

- Utilize a PLC approach to add to the exceptional needs understanding and investment of the entire building.

- Provide incentives for teachers, administrators, and staff to complete additional training offered locally or in cooperation with higher education. Training in adaptation, differentiation, and effective intervention during behavioral challenges would be most beneficial. Training in underlying legal aspects of education would be of tremendous value as well.

- Improve collaboration by implementing one or more of the following strategies:

- Establish mentoring relationships that go beyond initial orientation concerns and address best teaching practice as well.

o Modify hiring goals in such a way as to secure and retain at least one dualcertified (Regular education/Special education) teacher at each grade level in K-8. (Grades 9-12 are more specialized and would not require the same fit).

- Establish an articulated practice that enhances collaboration and allows teachers to regularly move in and out of roles - and helps to avoid burnout while strengthening understanding, investment, and establishment of "TEAM" within the school.

13

https://in.nau.edu/ejournal/ 
- Address recruitment and retention efforts by implementing one or more of the following strategies:

○ Recognize the added "weight" placed on special educators through compensation.

○ Recognize the added "strengths" of special educators by redefining leadership structures in such a way that taps their skills and energies for leadership challenges throughout the building or across the district.

- Emphasize to ALL prospective employees that this district and its schools are "employers of choice" and, as a result of improvements offered to this point, the type of place leaders can grow and truly make a difference.

\section{Conclusion}

The most appropriate remaining question might just be - Why should school leaders accept and invest in the viewpoints and arguments advanced within this article? The response to said question serves as an opportunity to summarize the information that has been laid out. It is as follows: The study group that engaged in this undertaking knew - as teachers, interns, students, and prospective leaders - that special education is an extremely challenging aspect of the total educational operation that cannot afford to be overlooked. They recognized that their training did not sufficiently prepare them for this responsibility, and this perception was strongly reinforced by the data integrated into this article. Positive examples of leadership have been shared during the completion of this project. The reality that took shape through this collective effort, however, amplified the understanding of the inability to deal with special education that often frustrates principals.

Special education came into being as part of a national awakening stemming from racial segregation (Esteves \& Rao, 2008), and renewed commitment to addressing injustices taking place in our schools and across society. In that it is difficult to package and replicate insights and convictions such as those just referenced - laws and policies again became that straightforward mechanism through which longstanding grievances were to be remedied. Unfortunately, the compliance mentality that schools are working under (Hughes, 2019; Hughes et al., 2019; Hughes and Davidson, 2020) frequently does far more to ensure the status quo than it does to introduce new ways of thinking or invigorate insightful leadership. This team documented decades worth of combined observations. Then they chose to advance that there are better ways to lead a school inclusively - and agreed that effort begins by closing the divide described by Bjorn et al., (2015).

The viewpoints expressed within this article may seem strong. They may, perhaps, even appear to be biased on behalf of those in special education. The makeup of this team was overwhelmingly from a regular education background and not dominated by those hailing from an exceptional needs orientation. This undertaking was directed toward promoting and supporting effective leadership for all students and all stakeholders in a school - including those who are affiliated with special education programming. The vision of the team was to understand better how to be effective leaders in an area where many lacked preparation. They are of a mind that they made important strides in that regard. It is their hope that disseminating their insights will benefit others including fledgling administrators who will likely face similar challenges - and likely do so without benefit of formal training in the area of special education. 


\section{References}

Bjorn, P., Aro, M., Kopoen, T., Fuchs, L., \& Fuchs, D. (2015). The many faces of special education within RTI frameworks in the United States and Finland. Learning Disability Quarterly, 1(9), DOI: 10.1177/0731948715594787, 1-9.

Cochran-Smith, M., \& Dudley-Marling, C. (2012). Diversity in teacher education and special education: The issues that divide. Journal of Teacher Education, 3, 237-244.

Creswell, J., \& Poth, C. (2018). Quality inquiry \& research design: Choosing among five approaches. Thousand Oaks, CA: Sage Publications, Inc.

Decker, J. (2014). Legal literacy in education: An ideal time to increase research, advocacy, and action. Education Law Reporter, 304 (1), 679-696.

Decker, J., \& Brady, K. (2016). Increasing school employees' special education legal literacy. Journal of School Public Relations, (36), 231-259.

English, F., \& Ehrich, C. (2016). Leading beautifully: Educational leadership as connoisseurship. New York, N.Y: Routledge.

Esteves, K., \& Rao, S. (2008). The evolution of special education: Retracing legal milestones in American history. Principal. Retrieved February 22, 2020 from https://www.naesp.org/sites/default/files/resources/1/Principal/2008/N-Oweb2.pdf.

Fuchs, D., Fuchs, L., \& Compton, D. (2012). Smart RTI: A next-generation approach to multilevel prevention. Exceptional Children, 78, 263-279.

Fullan, M., \& Kirtman, L. (2019). Coherent school leadership: Forging clarity from complexity. Alexandria, VA. ASCD.

Hickman, B. (2017). A case study: How a state education agency leads the implementation of results driven accountability. ProQuest 10685214.

Hughes, T. (2014). Hiring at risk: Time to ensure hiring really is the most important thing we do. International Journal of Educational Leadership Preparation. NCPEA Press, 8(1), 90-102.

Hughes, T. (2019). Mentoring school leaders through cultural conflict. Research in Educational Administration \& Leadership, 4 (3), 591-622. DOI: 10.30828/real/2019.3.6

Hughes, T., \& Mouw, J. (2017). Getting more than was registered for: Reciprocal benefits from post-graduate faculty e-mentoring. International Journal for Cross-Disciplinary Subjects in Education (IJCDSE), 8 (1), 2944 - 2953. 
Hughes, T., Caslin, J., Foss, C., Larsen, A., Loffer, J, \& Sacco, K. (2019). Leading through conflict with critical thinking and problem-solving. International Journal for CrossDisciplinary Subjects in Education, 10(4), 4142-4126.

Hughes, T., \& Davidson, F. (2020). Leading through conflict with credibility. In R. Papa (Ed.), [Oxford] Encyclopedia of Educational Administration. New York, N.Y.: Oxford University Press.

Jenkins, D. (2019). Exploring the lived experiences of becoming and being a leadership educator: A phenomenological inquiry. Journal of Leadership Education. DOI:10.12806/v18/13/R10, July 2019 pp 141-157.

Mader, J. (2017). How Teacher Training Hinders Special-Needs Students. Retrieved March 22, 2020 from https://www.theatlantic.com/education/archive/2017/03/how-teacher-traininghinders-special-needs-students/518286/

Miller, P. (2018). The nature of school leadership: Global practice perspectives, London: Palgrave Macmillan.

National Policy Board for Educational Administration. (2015). Professional standards for educational leaders 2015. Reston, VA: Author

Ramos, G., \& Hughes, T. (2020). Could more holistic policy addressing classroom discipline help mitigate teacher attrition? eJournal of Education Policy, 21(1). https://doi.org/10.37803/ejepS2002

Schneider, T. (2020) A social constructivist grounded theory of school principal legal learning. Journal of Research on Leadership Education. 1(17). DOI: 10.177/1942775120902191.

Werts, M., \& Carpenter, E. (2013). Implementation of tasks in RTI. Perceptions of special education teachers. Teacher Education and Special Education: The Journal of the Teacher Education, Division of the Council for Exceptional Children, 3, 247-257. 